\title{
A POLIFONIA E OS PRINCÍPIOS ARGUMENTATIVOS SUBJACENTES AO DISCURSO INDÍGENA GUARANI
}

\author{
Daniele Alves Inácio*
}

\begin{abstract}
RESUMO: Este artigo tem como objetivo evidenciar os princípios argumentativos subjacentes ao discurso indígena guarani. Para tanto, sustenta-se teoricamente na perspectiva da Teoria da Argumentação na Língua, desenvolvida por Ducrot (1984, 1988, 1989) e Anscombre e Ducrot (1995). O corpus utilizado na análise está constituído pela narrativa oral de um adulto indígena guarani falante do guarani e do português do Brasil. A análise dos dados aponta para o fato de que o informante utiliza os princípios argumentativos ligados especificamente à comunidade indígena subjacentes às perspectivas enunciativas apresentadas em seus enunciados, orientando o locutor para determinadas conclusões. Também evidenciamos que as diferentes vozes presentes do discurso indígena guarani do informante reiteram alguns topoi, o que confere maior força argumentativa aos enunciados em que intervêm.
\end{abstract}

PALAVRAS-CHAVE: Enunciação - Polifonia - Princípio Argumentativo

$\boldsymbol{R} \boldsymbol{E} \boldsymbol{S U} \boldsymbol{M} \boldsymbol{E}:$ Cet article vise à mettre en évidence les principes argumentatifs sous-jacents au discours indigène guarani. Pour cela, on se base théoriquement sur la perspective de la Théorie de l'argumentation dans la langue, développée par Ducrot (1984, 1988, 1989) et par Anscombre et Ducrot (1995). Le corpus utilisé pour l'analyse est constitué par le récit oral d'un parlant adulte indigène guarani qui parle le guarani et le portugais du Brésil. L'analyse des donnés indique que l'informateur utilise les principes argumentatifs liés spécifiquement à la communauté indigène, sous-jacents aux perspectives enonciatives présentés dans ses énoncés, orientant le locuteur vers certaines conclusions. Nous avons aussi remarqué que les différentes voix présentes dans le discours de l'informateur réitérent certains topoi, ce qui donne plus de force argumentative aux énoncés où il intervient.

MOTS-CLÉS: Énonciation - Polyphonie - Principe Argumentatif

\section{INTRODUÇÃO}

No início dos anos oitenta, Oswald Ducrot e Jean-Claude Anscombre criaram a Teoria da Argumentação na Língua (TAL). De acordo com os pressupostos defendidos pelos autores, a argumentação está inscrita na própria língua e a partir dela podemos analisar a argumentação produzida na/pela linguagem, considerando a diversidade e o dinamismo linguísticos inerentes ao uso.

Essa teoria desenvolvida pelos autores se opõe à concepção tradicional, que defende a tese de que a argumentação está nos fatos. De acordo com a tradição, um discurso para ser considerado argumentativo deve conter dois segmentos (argumento e conclusão) sendo que o argumento indica um fato passível de ser julgado verdadeiro ou falso independente da conclusão que possa dele derivar. Pela Teoria da Argumentação na Língua, as palavras não possuem sentido completo antes de tirarmos conclusões delas. Portanto, não há possibilidade de um argumento ser entendido antes de sua conclusão. A tese defendida é a de que as possibilidades argumentativas não são determinadas pelos fatos, mas pelas formas linguísticas. Tais formas orientam algumas

\footnotetext{
* Especialista em Estudos Linguísticos do Texto 2008-2009 - UFRGS/E-mail:danicoult@yahoo.com.br.
} 
argumentações e não outras e neste sentido diz-se que a argumentação está na própria língua e não fora dela.

A noção de polifonia como ligada à noção de topoi, objeto teórico deste estudo, apresenta-se como uma das fases da Teoria da Argumentação na Língua. Nesse momento da teoria, um discurso é concebido argumentativo porque constituído por dois segmentos, sendo um o argumento e o outro a conclusão. Os dois segmentos constituem apenas um enunciado e isso ocorre porque a passagem do argumento para a conclusão se dá a partir de um princípio argumentativo convocado pelo locutor, o topos.

Nessa perspectiva polifônica, Ducrot contesta a unicidade do sujeito falante em seu discurso e defende que o autor de um enunciado (sujeito empírico) não se expressa diretamente, mas o faz por meio da figura de um locutor (sujeito discursivo), que põe em cena diferentes pontos de vista. Isso mostra que o sentido de um enunciado nasce da confrontação das diferentes vozes que ali aparecem. Na versão dos Topoi, o autor concebe que os pontos de vista distintos de um enunciado evocam princípios argumentativos a partir dos quais o locutor argumenta, ora se opondo, ora aprovando e ora se identificando com esses pontos de vista.

Ao ler os trabalhos ligados a essa perspectiva, e trabalho realizado pelo autor em 2007 sobre diferentes perspectivas a essa, constituído por relatos indígena guarani, sentimo-nos instigados a verificar os princípios argumentativos subjacentes ao discurso indígena guarani, corpus já constituído para o trabalho de conclusão de graduação. Nesse caso, o objeto de análise deste estudo constitui-se de relatos pessoais orais de um índio guarani adulto falante do português e também da sua língua nativa, o guarani. A curiosidade pela questão surgiu na conversa entre professor e aluno, na qual emergiram os seguintes questionamentos: que princípios argumentativos podem estar subjacentes ao discurso do indígena? Como se apresenta a polifonia em seu discurso? Para respondermos a tais questionamentos, nosso estudo organiza-se em: 1) introdução, 2) referencial teórico, 3) metodologia, 4) análise dos dados e 5) considerações finais.

\section{ENUNCIAÇÃO, POLIFONIA E ARGUMENTAÇÃO}

Ancorado no trabalho de Saussure, e orientado pelas idéias de Benveniste, Oswald Ducrot situa seus estudos no interior da Linguística da Enunciação. Na sua visão, a enunciação é "o acontecimento constituído pelo aparecimento do enunciado" (DUCROT, 1987, p. 168). Assim, partindo do pressuposto de que o enunciado é o produto da enunciação e de que o que interessa são as figuras enunciativas que constroem o sentido no discurso, o autor propõe a chamada Teoria da Argumentação na Língua, cujo princípio básico é de que a argumentação está inscrita na língua. O que contraria a tradicional concepção de que a argumentação estaria nos fatos. Ou seja, segundo Ducrot (op. cit) a relação argumentativa está intrinsecamente ligada ao discurso e não deduzida de informações.

O valor da palavra atualiza no discurso o sentido argumentativo, conforme enfatiza Ducrot (id., 2005, p. 14) na seguinte passagem:

O mundo aparece, no enunciado, por meio da exploração discursiva do qual ele é objeto (...) o que preexiste à fala é uma situação sem limites e sem estrutura: a fala traz com ela os limites e os pontos de vista que tornam essa situação utilizável para a interpretação. 
Vemos em Ducrot (op. cit.) que é o contexto discursivo que produz sentido, visto que a palavra se atualiza no discurso.

A teoria polifônica da enunciação, proposta por Oswald Ducrot (1987), contesta o pressuposto da unicidade do sujeito falante, ou seja, o de que cada enunciado possui um único sujeito. Para ele, o sentido de um enunciado é a descrição de sua enunciação, que consiste na distinção das vozes de diferentes figuras enunciativas. $\mathrm{O}$ autor, ou sujeito empírico, é aquele que cria o texto, é o sujeito do mundo real. O locutor é o que assume a responsabilidade pela ocorrência do enunciado. Já os enunciadores são a fonte de diferentes pontos de vista manifestos na enunciação.

Ducrot (op. cit) ao esboçar a sua teoria polifônica, distingue dois tipos de polifonia, a de locutor e a de enunciador. A distinção entre os dois tipos de polifonia será apresentada a partir de idéias de Silva (1996). Ducrot, como mostra a autora, assinala a primeira forma de polifonia, através do discurso relatado, como vemos no exemplo 'Se Pedro diz< João me disse: "eu virei">', podem encontrar-se duas marcas de primeira pessoa que remetem a dois seres diferentes, evidenciando dois locutores distintos, o primeiro sendo relacionado a Pedro e o segundo a João. Por isso, Ducrot, conforme Silva (op. cit.) prefere caracterizar o discurso relatado direto como consistindo, fundamentalmente, em uma apresentação de uma enunciação dupla: o próprio sentido do enunciado atribuiria à enunciação dois locutores distintos, eventualmente subordinados.

Além de assinalar tal forma de polifonia em que há dois locutores distintos em caso de "dupla enunciação", a noção de enunciador permite a Ducrot descrever a segunda forma de polifonia: aquela que ocorre quando se encontra em um discurso a voz de alguém que não tenha as propriedades que se atribui ao locutor. São os "enunciadores", que se expressam através da enunciação, aparecendo somente as manifestações de suas posições, mas não, no sentido material, suas "falas". O autor denomina esses pontos de vista, estranhos ao do locutor como "enunciadores", conforme vemos no conceito explicado pelo próprio autor.

\footnotetext{
Chamo "enunciadores" esses seres que são considerados como se expressando através da enunciação, sem que para tanto se lhe atribuam palavras precisas; se eles "falam" é somente no sentido em que a enunciação é vista como expressando seu ponto de vista, sua posição, sua atitude, mas não no sentido material do termo, suas palavras. (DUCROT, 1987, p. 192)
}

Com a Teoria da Polifonia, Ducrot (op. cit) defende que o sentido de um enunciado configura-se não só através dos termos nele contidos, mas igualmente através das "figuras" enunciativas que apresenta, as quais remetem ao contexto da enunciação. Tais "figuras" abrangem a diversidade de representação do sujeito no enunciado, fazendo, por isso, parte de seu sentido.

Vemos assim que, em sua teoria, Ducrot (op. cit) questiona a presença de um único sujeito nos enunciados, e apresenta a tese de que é preciso distinguir entre os sujeitos de um enunciado pelo menos dois tipos de personagens, o locutor e os enunciadores. Os locutores são os responsáveis pelo enunciado produzido, já os enunciadores são as origens dos pontos de vista manifestados na enunciação. Assim sendo, o sentido do enunciado estaria não só nas várias vozes que se manifestam através dele, mas na posição do locutor frente aos enunciadores que são por ele mobilizados na produção do enunciado. 
Ducrot, em fase posterior de seu estudo, alia a concepção polifônica do sentido à Teoria da Argumentação na Língua associando-a à Teoria dos Topoi ${ }^{1}$ na descrição do sentido dos enunciados, uma vez que o aspecto argumentativo de um enunciado faz parte de seu sentido, pois, na medida em que o enunciado e seu sentido são veiculados pela enunciação, as "propriedades jurídicas, argumentativas, causais, por eles atribuídas a ela, não poderiam ser vistas como hipóteses feitas a propósito da enunciação, mas como a constituindo" (DUCROT, 1987, p. 177). Nessa concepção, a descrição do sentido consiste em observar nos enunciados a fonte dos diferentes pontos de vista e o princípio argumentativo (topos) que evoca uma confluência de vozes (Polifonia).

\section{POLIFONIA E PRINCÍPIOS ARGUMENTATIVOS}

A Teoria da Argumentação na Língua de Ducrot (1988) defende a idéia de que a relação argumento/ conclusão, que constitui o sentido dos enunciados de uma língua, é garantida (e/ou mediada) por um lugar comum argumentativo, um princípio argumentativo, o topos.

Vemos como essa tese é concebida a partir dos seguintes exemplos:

(1) Lucas estudou pouco.

(2) Lucas estudou um pouco.

Esses enunciados, se produzidos em contexto de realização de uma prova, apresentam conclusões implícitas de que "Lucas não vai bem na prova" (enunciado 1) e de que "Lucas irá bem na prova" (enunciado 2). Segundo Ducrot, na relação argumento e conclusão há um princípio argumentativo evocado de que "quando se estuda, se vai bem na prova". Tal princípio chamado de topos, segundo Ducrot (1989), é o que possibilita a passagem do argumento à conclusão. O topos apresenta as seguintes propriedades: a universalidade, a generalidade e a gradualidade.

O topos é universal, porque é partilhado por uma comunidade linguística, na qual esteja aquele que produz o enunciado e a quem o enunciado é dirigido, sendo o topos o lugar comum ao enunciador e a outras pessoas. Outra característica do topos é a generalidade, pois vale para muito além do que a situação em que é aplicado, vale para um grande número de situações diferenciadas. Conforme Azevedo (2007), argumentar consiste em integrar o estado de coisas particular de que se fala a uma categoria muito mais geral e para a qual o topos utilizado é considerado válido. A terceira propriedade é a gradualidade que consiste no fato de que o topos põe em relação duas gradações, as quais, conforme Silva (1996), mostram que a relação argumento/ conclusão é gradual por natureza, pelo fato de que um argumento é mais ou menos forte para uma dada conclusão. Devido à gradualidade, o topos pode variar seus valores argumentativos. No exemplo: "Eu persisti muito, ganhei o emprego", o enunciado apresenta uma relação argumentativa entre "persistir muito" e "ganhar o emprego" O enunciado "Eu persisti muito" só é válido para o enunciado - conclusão através do princípio geral 'topos' compartilhado pelos falantes no qual "a persistência leva ao êxito em conquistas". A universalidade está ligada ao fato de o enunciado ser partilhado por uma comunidade linguística, a generalidade se apresenta porque o mesmo pode ser aplicado a situações semelhantes como a de conquistas profissionais que requerem persistência e, por último, a gradualidade estaria entre a intensidade de persistência e o ganho do emprego.

Relacionando Teoria da Polifonia à noção de topos, Ducrot conclui que o enunciador quando argumenta escolhe um topos e localiza a situação de que fala em

\footnotetext{
${ }^{1}$ topoi é o plural grego de topos.
} 
uma determinada gradualidade. Nessa concepção, a descrição do sentido consiste em observar nos enunciados a fonte dos diferentes pontos de vista e o princípio argumentativo (topos) que evoca, com a verificação da atitude do locutor em relação a tais pontos de vista (oposição, aprovação e identificação). No exemplo "Carlos estudou pouco, mas ficou bem classificado no concurso", são obtidos quatro enunciadores (E1, E2, E3 e E4): E1 apresenta o ponto de vista de que "Carlos estudou pouco", E2 conclui sobre "a má classificação de Carlos no concurso", E3 afirma a "boa classificação de Carlos no concurso" e E4 conclui, a partir de E3, que "outros fatores, além do estudo, auxiliam na boa classificação de concursos". O locutor, neste caso, aprova E1 e E2, mas se identifica com E3 e E4. Esses quatro enunciadores argumentam, convocando o topos "o estudo leva ao êxito em concursos".

De acordo com Ducrot, descrever o sentido de um enunciado significa descobrir o topos utilizado pelo locutor que está na base da argumentação. Dessa maneira, descrever a semântica de um enunciado é analisar os elementos apresentados pelos diferentes enunciadores expressos pelo enunciado, considerando-se que a posição dos enunciadores consiste em um princípio argumentativo, um topos. Assim, a integração dessas duas teorias permite ao autor descrever semanticamente um enunciado para mostrar que o locutor constitui a sua argumentação a partir de um debate de posições, constituídas a partir da convocação de certos princípios argumentativos (lugar comum partilhado por uma dada comunidade) trazidos pelo locutor em seu discurso, considerado produto da enunciação.

É nessa linha enunciativo-argumentativa que delinearemos nossa metodologia na seção seguinte.

\section{METODOLOGIA}

\section{O corpus: o sujeito da pesquisa}

O corpus do trabalho representa um recorte de uma pesquisa já realizada pelo autor em 2007, constituída por outras perspectivas teóricas, através do discurso indígena guarani. A coleta de dados realizou-se na aldeia dos índios Guarani, conhecida como Araçá ${ }^{2}$, fixada há vinte e cinco anos na BR 119, no bairro Petin, que se localiza na região de Guaíba. O recorte abrange uma coleta de dados de linguagem oral, de quarenta minutos, sendo o corpus formado por um falante bilíngue, que usa como língua nativa o guarani, mas também, o português para uma melhor integração fora da comunidade em que vive. O sujeito escolhido para a pesquisa é do sexo masculino, com 23 anos e com ensino fundamental completo, o que possibilitou a coleta, uma vez que as crianças da comunidade falam apenas a língua nativa e os índios mais velhos usam o guarani na aldeia Araçá. Logo, a escolha desse sujeito da pesquisa deu-se pelo fato de haver maior facilidade em produzir enunciados maiores e, dessa forma, uma importante obtenção de dados para a análise.

O corpus foi constituído por relatos pessoais sobre a comunidade e a aldeia Araçá. Tais relatos foram obtidos a partir de perguntas da investigadora sobre a vida na aldeia. Nesse texto, ocorrerá a análise empreendida pelo recorte do relato do índio Guarani.

\footnotetext{
${ }^{2}$ Segundo o autor Luis Fernando Laroque (2002), o grupo da aldeia Araçá já esteve em torno de 90 pessoas, mas hoje o grupo é formado por 27 indivíduos.
} 


\section{Procedimentos de coleta e seleção de corpus}

Os procedimentos utilizados na entrevista foram de suma importância para a obtenção de enunciados em que o informante falava de maneira natural e espontânea, mesmo com a presença de uma pessoa não familiar, no caso, a investigadora.

As entrevistas aconteceram na aldeia Araçá, através de gravações da fala do indígena e de filmagem do informante, com o objetivo de recuperar a sua fala, visto que, devido à influência da língua nativa, o entrevistado mistura as línguas e utiliza gestos para um melhor entendimento. Além disso, as entrevistas ocorreram em um local dentro da aldeia, onde todos os membros do grupo estavam presentes, inclusive as crianças falantes apenas da língua nativa, o que nos levou a ter uma boa concentração para a coleta. Nesse caso, o vídeo tornou-se, então, um facilitador da transcrição. Houve dois encontros na aldeia: o primeiro serviu para uma aproximação com o grupo, que se mostrou bastante receptivo. A naturalidade da relação foi tanta que o grupo sentiu-se desinibido a ponto de deslocar-se de sua aldeia até outra com a investigadora; o segundo encontro serviu para a coleta de dados. As entrevistas foram feitas de maneira bastante informal, já que o grupo estava à vontade. Foram usados os seguintes procedimentos: para que o Guarani ficasse de forma natural, foi permitido que todo o grupo compartilhasse o momento das entrevistas. $\mathrm{O}$ objetivo era de permitir uma aproximação maior a fim de que assuntos sobre a aldeia e sobre a cultura guarani servissem de gancho para o relato de modo que a fala fosse o mais natural possível.

As entrevistas consistiram em perguntas sobre questões ligadas à vida na aldeia e de respostas a essas perguntas. Neste estudo, foram selecionados blocos de interação pergunta-resposta para fins de análise.

Numa perspectiva enunciativa, cada discurso, como produto da enunciação, é considerado único e irrepetível. Nesse caso, a quantidade de dados e a busca de generalização não é relevante. Por isso, recortamos do corpus alguns blocos perguntas/respostas para ilustrar o debate de pontos de vista que aparecem no discurso de um falante de uma comunidade indígena. Cabe ressaltar que nossa análise é qualitativa e não quantitativa.

\section{Segmentação do corpus e procedimentos de análise}

A segmentação do corpus teve as seguintes etapas. Na primeira, observamos como os enunciados estão constituídos nos blocos pergunta - resposta. A partir dos estudos de Ducrot (1988), observamos a relação argumento - conclusão em cada um. $\mathrm{Na}$ segunda etapa, buscamos selecionar os enunciados com indicações polifônicas: marcas de negação, de pressuposição (adjetivos, advérbios...), além do uso do "mas".

Após a segmentação do corpus, partimos para a análise propriamente dita, que foi efetivada com base na noção de polifonia aliada à de topoi (princípios argumentativos). Para tanto, foram destacadas na análise as vozes e os princípios argumentativos correspondentes, que subjazem ao discurso do sujeito da pesquisa. Dentro do colocado, exemplificamos a seguir como analisamos o discurso do informante. Por isso, ilustramos com enunciados, retirados de uma entrevista da Revista Língua Portuguesa com o colunista da Folha de São Paulo, José Simão, os procedimentos de análise:

*LÍNGUA ${ }^{3}$ : você ainda tem predileção por textos mais intimistas?

\footnotetext{
${ }^{3}$ Revista Língua Portuguesa, Ano II - NÚMERO 24 - Outubro de 2007. 
*JOSÉ: não, eu gosto de texto, e ponto.

Temos nesse discurso um tema (estilos e escolhas adotadas pelo colunista), proposto na entrevista, que faz com que os enunciados de José Simão retomem o tema. Percebemos nesse bloco pergunta - resposta a seguinte relação argumento/ conclusão: na fala do entrevistador, temos o argumento ter predileção por texto intimista antes que conduz à conclusão portanto, gostar deste tipo de texto agora. Já na fala de José Simão, ocorre o argumento não tenho predileção por texto intimista que encaminha à conclusão portanto, gostar de todo tipo de texto.

Para mostrar o funcionamento polifônico com seus princípios argumentativos subjacentes ao discurso, procedemos do seguinte modo: foi destacada a expressão que indica a presença de diferentes vozes no discurso. No caso da entrevista, temos como índice de polifonia o uso do "ainda" pelo entrevistador que apresenta os seguintes enunciadores:

E1> José Simão teria antes predileção por textos mais intimistas.

E2> José Simão continua tendo predileção por textos mais intimistas.

Esses enunciadores evocam o seguinte princípio argumentativo: quem escreve gosta de ler e tem preferências de leitura. Esse princípio é universal na nossa cultura, é geral, porque se aplica a outras situações e é gradual porque se supõe que quanto mais se escreve mais se gosta de ler textos preferenciais e quanto menos se escreve menos se gosta de ler textos preferenciais.

A metodologia de análise aqui ilustrada é a mesma utilizada na análise dos enunciados recortados, o qual verificamos os princípios argumentativos que subjazem à polifonia presente no discurso indígena guarani.

\section{ANÁlISE DOS DADOS: O FUNCIONAMENTO POLIFÔNICO E OS PRINCÍPIOS ARGUMENTATIVOS NO DISCURSO INDÍGENA GUARANI}

Nos procedimentos de análise, os dados foram analisados, de maneira que tentamos evidenciar como o índio Guarani mostra a confluência de vozes em seus relatos pessoais, assim como os topoi e suas respectivas formas tópicas evocados por tais vozes.

A seguir passamos a destacar passagens para verificar a análise realizada.

* DAI : A FUNAI vem aqui?

* Guarani: Onde? a FUNAI não vem, agenti não sabe nem da onde é a FUNAI.

Temos neste discurso um tema (cultura Guarani), proposto na entrevista, que faz com que os enunciados do indígena retomem o tema. Percebemos neste bloco pergunta - resposta a seguinte relação argumento/ conclusão: na fala da investigadora ocorre "ser indígena PORTANTO receber a visita da FUNAI". O argumento da investigadora está implícito na pergunta que indica um princípio argumentativo em seu ponto de vista de que "uma comunidade de indígenas deve receber a visita da FUNAI (Fundação Nacional dos Índios). Já a fala do informante mostra um locutor que desconhece a FUNAI: "a FUNAI não vem, PORTANTO, não sabemos onde fica".

No enunciado acima, temos, na relação com a pergunta do entrevistador, o discurso do informante apresentando como índice de polifonia o uso do "nem" e "não" pelo entrevistado que evoca os seguintes enunciadores:

E1: a FUNAI deveria ir à comunidade indígena

E2: a FUNAI não vai à comunidade

\footnotetext{
${ }^{4}$ Sem identificação para apreciação corresponde à entrevistadora do índio Guarani.
} 
Levando em conta o par pergunta (fala da investigadora) e resposta (fala do informante), percebemos que os enunciadores evocam o seguinte princípio argumentativo: "comunidades indígenas devem receber visita da FUNAI". Esse princípio é universal em nossa cultura, também é geral no sentido de que pode aparecer em outros discursos, e é gradual porque quanto mais uma comunidade se caracteriza como indígena mais a FUNAI deve visitar e quanto menos uma comunidade se caracteriza como indígena menos a FUNAI deve visitar.

Ligando isso à presença da palavra nem, vemos que o locutor relaciona o não comparecimento da FUNAI e o local onde a FUNAI deveria atender, devido ao princípio geral já mencionado, compartilhado por ele e seu interlocutor. Com isso, os segmentos levam o interlocutor à conclusão de que o locutor assume que "deveria saber informações da FUNAI, que deveria ser atendido conforme suas necessidades, que deveria receber a visita periódica da FUNAI", etc.

$\mathrm{Na}$ continuidade das análises, destacamos abaixo outro bloco pergunta - resposta para verificar seu funcionamento polifônico.

* DAI: De que são feitas as habitações de vocês? quais os materiais?

* Guarani: Olha, antigamenti era de madeira e taquara, mas hoji em dia como agenti não tem material, temo que comprá a lona, agora ta usando a telha, só qui a telha pra nóis não é suficienti purque no verão ela não segura, muitu quenti e nu frio ela passa tudo, agenti não se acostuma só qui aos poucos agenti vai se acostumandu.

$\mathrm{Na}$ fala da investigadora, há um locutor constituído que apresenta a seguinte relação argumento/ conclusão: "construir habitações, PORTANTO, precisar de materiais". Seguindo essa orientação argumentativa, o entrevistado apresenta um locutor no seu discurso que, num primeiro momento, mostra as seguintes argumentações: "construção antes era de madeira e taquara, PORTANTO, materiais disponíveis"; "hoje em dia não tem material disponível, portanto, tem que comprar".

Essas argumentações constituem-se devido à marca "mas" utilizada no discurso. Esse "mas" evoca os seguintes enunciadores, instanciando a polifonia no discurso, como vemos na descrição abaixo:

E1: antigamente havia madeira e taquara à disposição.

E2: os índios não precisavam comprar material.

E3: hoje em dia não tem material (madeira e taquara) para os índios.

E4: os índios têm que comprar.

A negação utilizada, no segundo segmento desse primeiro enunciado, estabelece relação com as argumentações anteriores. Com o da investigadora, que traz a relação "habitação/ material" e com o primeiro segmento da fala do entrevistado que coloca o argumento de que "antes tinha material, como madeira e taquara". Ao afirmar que "hoji agenti não tem material", o locutor, do discurso do entrevistado, constitui um enunciador que nega as afirmações anteriores, atestando a polifonia no discurso, como vemos na descrição abaixo:

E1: antes ter material para construir habitação.

E2: hoje não ter material para construir habitação.

$\mathrm{O}$ segundo enunciador encaminha à conclusão de que "tem que comprar material". Além disso, na passagem mas hoji em dia como agenti não tem material, temo que comprá a lona, vemos a argumentação constituída na relação com o segmento anterior que afirma que as construções antigamenti era de madeira e taquara. Nessa relação entre antigamente ter material é encadeada com hoji em dia como agenti não tem material. Nesse caso, o articulador marca a relação entre ter material e não ter material. Essa oposição tem como conclusão temo que comprá lona. 
Além disso, ao afirmar que "só qui a telha pra nóis não é suficienti" e "só qui aos poucos agenti vai se acostumandu" o locutor, do discurso do entrevistado, evoca os seguintes enunciadores, instanciando a polifonia no discurso, como vemos na descrição a seguir:

E1: o material de agora é comprado.

E2: o material de agora não é como o de antes.

E3: o material não é como a madeira e taquara, só que também é utilizado na habitação.

O terceiro enunciador encaminha à conclusão de que "o material comprado é utilizado na habitação agora".

Observando que o discurso foi produzido por um indígena bilíngue, sendo o guarani a sua língua nativa, percebemos que os enunciadores evocam o seguinte princípio argumentativo: construir habitações depende da disponibilidade de materiais. Esse princípio é universal na nossa cultura e também é geral no sentido de que pode aparecer em outros discursos, e é gradual porque quanto mais material, mais casas construídas e quanto menos material, menos habitações construídas.

Ainda na tentativa de evidenciar como o índio Guarani mostra a confluência de vozes em seus relatos pessoais, assim como os topoi e suas respectivas formas tópicas evocados por tais vozes, ilustremos outro bloco pergunta - resposta através do enunciado produzido pelo indígena:

Ainda na passagem agora ta usando a telha, só qui a telha pra nóis não é suficienti purque no verão ela não segura, muitu quenti e nu frio ela passa tudo, agenti não se acostuma só qui aos poucos agenti vai se acostumandu, temos polifonia através de pressuposição, já que o locutor argumenta que a telha não segura, é muito quente no verão e no frio ela passa tudo. Aqui vemos o locutor constituir a polifonia no discurso: E1: antes o material era suficiente, porque protegia do calor no verão e do frio no inverno

E2: a telha, material comprado de hoje, não é suficiente, porque não protege do calor no verão nem do frio no inverno.

Esses enunciadores argumentam a partir do topos de que bons materiais precisam proteger a habitação do calor e do frio. Esse topos é universal em nossa comunidade, é geral e gradual: quanto melhor o material mais protege a habitação; quanto pior o material menos protege. Na continuidade, vemos o locutor argumentar em favor da necessidade de se acostumar com o material. Por isso, a relação entre não se acostuma com só qui aos poucos agenti vai se acostumandu instancia um ponto de vista através de só qui e com o continuativo do gerúndio de que com materiais que não protegem vai se acostumando aos poucos oposto à posição de que com materiais que protegem a gente se acostuma rápido. Essas posições evocam o topos de que "com o que é bom nos acostumamos rápido", que é universal, geral e gradual "quanto melhor algo mais rápido nos acostumamos" e de que "quanto pior algo mais difícil (menos rápido) para se acostumar.

$\mathrm{Na}$ passagem abaixo, vemos o informante argumentando sobre religião.

* DAÍ: E religião? acreditam em que Deus?

* Guarani: Olha, nós temo um criador, Anderu Tupã, vamu dize, voluntário de Deus qui trabalhá aqui na terra, quandu agenti passa necessidadi assim na saúdi, agenti sempri pedi para Anderu, pra genti vive bem sempre.

Temos neste discurso um tema (cultura religiosa Guarani), proposto na entrevista, que faz com que os enunciados do indígena retomem o tema. Percebe-se neste bloco pergunta - resposta a seguinte relação argumento/ conclusão: na fala da entrevistadora ocorre a relação "ter uma religião, PORTANTO, acreditar em um Deus"; 
e na fala do índio ocorre a relação "temos um criador, PORTANTO, acredita-se em um Deus"; "o voluntário de Deus trabalha na terra, PORTANTO, atende as necessidades.

Essas argumentações constituem-se devido à marca da oração adjetiva explicativa "que", transcrita "qui", utilizada no discurso e que instaura pressupostos. Esse "qui" evoca os seguintes enunciadores, instanciando a polifonia no discurso, como vemos na descrição abaixo:

E1: Deus atende as necessidades no céu.

E2: o voluntário de Deus atende as necessidades na terra.

E3: quando se passa necessidade, se pede ajuda ao voluntário.

A passagem "Anderu Tupã, vamu dize", no enunciado do entrevistado, tem função de ilustração do que é argumentado, o nome do voluntário de Deus na terra.

Considerando que o discurso foi produzido por um falante bilíngue, em que o guarani é sua língua nativa, percebemos que os enunciadores evocam o seguinte princípio argumentativo: o voluntário de Deus atende as necessidades na terra. Esse princípio é universal na cultura indígena guarani, é geral, porque o informante e demais membros de sua comunidade podem utilizar em outras situações e é gradual porque quanto mais se precisa de ajuda, mais se pede e quanto menos se precisa menos se pede.

Ligando isso à presença da palavra "qui", vemos que o locutor instancia o enunciador pressuposto de que há um Deus que trabalha fora da terra e de que o Voluntário de Deus, ligado à sua comunidade, trabalha na terra.

Com isso, o locutor defende que sua comunidade acredita num Deus e no seu voluntário, Anderu Tupã.

Mostramos com as análises mais uma vez, que a proposta deste estudo comprova os pressupostos teóricos defendidos por Oswald Ducrot: 1) o de que a argumentação está na língua; 2) o de que o sentido se constrói no discurso a partir do ato enunciativo relacionado a um sistema pré-existente e 3) o de que, a partir do ato enunciativo, é possível identificar a posição argumentativa do locutor responsável pela enunciação.

Procuramos nas análises aqui apresentadas responder aos questionamentos iniciais apresentados na introdução: 1) Que princípios argumentativos podem estar subjacentes ao discurso do indígena? Como se apresenta a polifonia em seu discurso?

As respostas a essas questões serão trazidas nas considerações finais.

\section{CONSIDERAÇÕES FINAIS}

Neste trabalho, pretendemos evidenciar que princípios argumentativos podem estar subjacentes ao discurso do indígena e como se apresenta a polifonia em seu discurso e, desta forma, os lugares de argumentação presentes na fala do índio guarani através da verificação dos topoi evocados pelas diferentes vozes dos enunciadores que se apresentam em seus relatos pessoais.

A Teoria da Argumentação na Língua, a qual embasa o estudo apresentado, ocupa-se com a análise sequencial de enunciados, logo, trabalhamos com conceitos que norteiam os trabalhos de Ducrot, quais sejam frase, enunciado, texto e discurso, a fim de que, nossos critérios fossem embasados na teoria. Nesse sentido, verificamos que os relatos pessoais do índio configuram-se como sequência de enunciados, constituindo o discurso, na relação entre o que é dito pelo guarani e o que é dito pela investigadora, que fornece temas, tais como FUNAI, religião e habitações indígenas, e dessa forma, já está evocando determinados topos e traçando o segmento argumentativo do indígena.

A versão da Teoria da Argumentação da Língua que utilizamos para a verificação da polifonia na fala do índio guarani é a Teoria dos Topoi (1995), na qual 
Anscombre e Ducrot afirmam a tese de que os enunciados pelos quais o locutor produz possuem argumentatividade, sob a qual subjaz um princípio argumentativo que os autores conceituam por topos. O princípio apresenta as características de universalidade, generalidade e gradualidade. Contudo, verificamos que o topos preenche apenas as características de universalidade e de generalidade. No entanto, verificamos que alguns princípios são universais e gerais somente no contexto da comunidade indígena, tal como aquele que aparece ligado ao discurso da religião: $o$ voluntário de Deus atende às necessidades na terra. Já outros, embora apareçam no discurso ligado ao índio, ocorrem na comunidade indígena e fora dela, conforme visto no topos "comunidades indigenas devem receber visita da FUNAI". Outros são mais universais e gerais, pois pertencem à sociedade de maneira geral, como aquele que ocorre no discurso ligado à habitação: bons materiais precisam proteger a habitação do calor e do frio.

Além destas considerações, outras importantes, ligadas à questão teórica e sua relação com a polifonia da fala do indígena podem ser assinaladas. Uma delas é que o índio bilíngue, falante da sua língua nativa e também do português, evidencia, em seus discursos, princípios argumentativos subjacentes às perspectivas enunciativas. Isso comprova um uso argumentativo da língua, visto sempre procurarem orientar o interlocutor para determinadas conclusões. A outra está ligada à questão de que os dados parecem apontar para o fato de que determinados topoi possibilitam que certos enunciados sejam produzidos pela comunidade indígena, e não, por outra comunidade, tal como "nós temo um criador, Anderu Tupã, vamu dize, voluntário de Deus qui trabalhá aqui na terra", em que consideramos natural ser dito por um indígena, e não, por um branco. Além disso, as análises dos relatos indígenas evidenciam que as diferentes vozes reiteram determinados topoi, como o de que "o voluntário de Deus atende as necessidades na terra". Tal uso reiterado de certos topoi, possivelmente, faça com que se coloquem como princípios que singularizam o discurso indígena.

As análises dos dados do indígena empreendidas até o momento parecem mostrar algumas questões importantes ligadas à Teoria da Argumentação na Língua. Uma delas diz respeito ao fato de que o informante utiliza alguns princípios argumentativos ligados especificamente à comunidade indígena subjacentes às perspectivas enunciativas apresentadas em seus enunciados, orientando o locutor para determinadas conclusões. Também subjazem ao discurso do informante princípios argumentativos da comunidade em geral, o que mostra a inserção dos índios cada vez mais na "cultura colonizada".

Essas considerações respondem ao nosso questionamento inicial sobre os princípios argumentativos subjacentes ao discurso indígena guarani e as diferentes vozes, e podem permitir uma reflexão maior em outros estudos com outros dados, a fim de que, possa servir de subsídio para estudos que possibilitem a formulação de atividades educativas nas aldeias indígenas.

\section{REFERÊNCIAS}

AZEVEDO, Tânia Maris de. Semântica argumentativa: uma possibilidade para a descrição do sentido do discurso. 2003. 135 f. Tese (Doutorado em Letras) - Faculdade de Letras, PUCRS, Porto Alegre, RS.

DUCROT, Oswald. $O$ dizer e o dito. Revisão técnica da tradução: Eduardo Guimarães. Campinas, SP: Pontes, 1987. 
Argumentação e "topoi" argumentativos. In: GUIMARÃES, Eduardo (org.) História e sentido na linguagem. Campinas, SP: Pontes, 1989.

GALLI, Mariângela Peccioli. Enunciação e discursividade em enunciados do cotidiano. Alfa: revista de linguística. São Paulo. v. 39, p.131-143, 1995.

SILVA, Carmem L. da Costa. Os princípios argumentativos subjacentes à polifonia da fala infantil. Letras de Hoje. Porto Alegre. v. 36, n. 4, p. 97 - 123: PUCRS, 1996. 